\title{
Long term mortality and cardiovascular morbidity increased in some patients with asymptomatic mitral valve prolapse
}

\author{
Avierinos J-F, Gersh BJ, Melton LJ 3rd, et al. Natural history of asymptomatic mitral valve prolapse in the community. \\ Circulation 2002;106:1355-61.
}

QUESTION: In patients with asymptomatic mitral valve prolapse (MVP), what is the prognosis of the disease?

\section{Design}

Inception cohort followed for a median of 5.4 years.

\section{Setting}

Olmsted County, Minnesota, USA.

\section{Patients}

833 patients (median age $47 \mathrm{y}$ ) with a first diagnosis of asymptomatic MVP, first suspected by auscultatory findings $(n=557)$ or found incidentally $(n=276)$, confirmed by echocardiography, who were residents of Olmsted County, Minnesota, USA for $\geq 1$ year before diagnosis. Exclusion criteria were notable dyspnoea, angina, or mitral surgery before diagnosis. Follow up was $97 \%$.

\section{Assessment of prognostic factors}

Clinical and echocardiographic variables. The degree of mitral regurgitation (MR) was stratified into 3 categories: absent or trivial, slight, and moderate to severe.

\section{Main outcome measures}

Total mortality, cardiovascular (CV) mortality, and CV morbidity.

Table 1 Outcome predictors and adjusted hazard ratios (HRs) for total and cardiovascular $(C V)$ mortality in asymptomatic mitral valve prolapse*

\begin{tabular}{lll}
$\begin{array}{l}\text { Outcome } \\
\text { predictors }\end{array}$ & $\begin{array}{l}\text { Total mortality } \\
\text { HRs }(95 \% \mathrm{CI})\end{array}$ & $\begin{array}{l}\text { CV mortality HRs } \\
\text { (CI) }\end{array}$ \\
$\begin{array}{l}\text { Moderate to severe } \\
\text { mitral } \\
\text { regurgitation }\end{array}$ & $1.8(1.03$ to 3.0$)$ & $3.0(1.5$ to 5.8$)$ \\
\hline $\begin{array}{l}\text { Ejection fraction } \\
<50 \%\end{array}$ & $2.3(1.05$ to 4.4$)$ & $3.8(1.6$ to 8.1$)$ \\
\hline
\end{tabular}

${ }^{*} \mathrm{HRs}$ adjusted for age, sex, and comorbid conditions.

Table 2. Outcome predictors and adjusted hazard ratios (HRs) for cardiovascular morbidity in asymptomatic mitral valve prolapset

\begin{tabular}{ll} 
Outcome predictors & $\begin{array}{l}\text { Cardiovascular morbidity } \\
\text { HRs }(95 \% \mathrm{Cl})\end{array}$ \\
Age $\geq 50 \mathrm{y}$ & $3.1(2.0$ to 5.0$)$ \\
\hline Left atrium $\geq 40 \mathrm{~mm}$ & $2.7(1.9$ to 3.8$)$ \\
\hline Slight mitral regurgitation & $3.6(2.0$ to 7.0$)$ \\
\hline $\begin{array}{l}\text { Moderate to severe mitral } \\
\text { regurgitation }\end{array}$ & $9.1(4.9$ to 18.3$)$ \\
\hline Flail leaflet & $2.6(1.5$ to 4.6$)$ \\
\hline Baseline atrial fibrillation & $2.0(1.2$ to 3.0$)$ \\
\hline
\end{tabular}

tHRs adjusted for age, sex, and comorbid conditions.
Main results

At median follow up of 5.4 years, 96 deaths (11.5\%) occurred and 171 patients (20.5\%) had CV morbidity. At 10 years, total mortality was $19 \%$, CV mortality was $9 \%$, and CV morbidity was 30\%. After adjusting for age, sex, and comorbid conditions, moderate to severe MR and ejection fraction $<50 \%$ were independent predictors of CV mortality (table 1). Several prognostic factors independently predicted CV morbidity (table 2).

\section{Conclusions}

In patients with asymptomatic mitral valve prolapse, mortality and cardiovascular (CV) morbidity increased over time. Several clinical and echocardiographic variables independently predicted total and CV mortality and CV morbidity.

\section{COMMENTARY}

The study by Avierinos $e t$ al assesses prognosis and risk factors for adverse outcome in patients with asymptomatic MVP. MVP is common in the general population and is usually treated as a benign diagnosis with a favourable outcome. This study provides data to allow clearer risk stratification of asymptomatic patients newly diagnosed with MVP. Patients with either of the 2 primary risk factors, an ejection fraction $<50 \%$ or at least moderate MR, were considered high risk. Compared with other groups over 10 years, patients at high risk had greater CV morbidity and mortality, with a $45 \%$ mortality rate. Patients with $\geq 2$ secondary risk factors (slight MR, flail leaflet, left atrium $\geq 40 \mathrm{~mm}$, atrial fibrillation, and age $\geq 50$ y) were at intermediate risk. Patients at intermediate risk had a 10 year survival similar to that expected but had $40 \%$ CV morbidity. Those with 1 or no secondary risk factors had outcome similar to that of the general population. In this community population, $52 \%$ were low risk, $30 \%$ were intermediate risk, and $18 \%$ were high risk at diagnosis.

This study looks only at patients who have been diagnosed with MVP, rather than at the true prevalence of MVP in the population. However, those diagnosed are more relevant to clinical practice because these are the patients who physicians treat in the office.

This is a well done study that adds to our ability to risk stratify newly diagnosed patients with asymptomatic MVP. Brigitta C Brott, MD University of Alabama at Birmingham Birmingham, Alabama, USA
Source of funding: in part, National Institutes of Health.

For correspondence: $\operatorname{Dr} M$

Enriquez-Sarano, Mayo Clinic, Rochester, $M N$, USA.

saranomaurice@ mayo.edu

Abstract and commentary also appear in ACP Journal Club. 